\title{
ESCOLA PÚBLICA DE ENSINO FUNDAMENTAL I EM PRESIDENTE PRUDENTE-SP NA REPÚBLICA POPULISTA (1945-1964)
}

Mariane Garcia, Derick A. Moraes Sanches, Mayara Pissutti Albano, Fabricia Fernandes Borges, Yeda Ruiz Maria, Sibila Corral de Arêa Leão Honda

Universidade do Oeste Paulista - UNOESTE, Faculdade de Engenharias e Arquitetura e Urbanismo, Presidente Prudente, SP. E-mail: sibila.honda@sibila.arq.br

\section{RESUMO}

Em 1979, foi aprovada a primeira legislação brasileira sobre parcelamento do solo urbano, que também exigia áreas para implantação de equipamentos de serviços públicos. Anteriormente a essa data, não havia controle e/ou direcionamento sobre a malha urbana. Ao mesmo tempo, a oferta de ensino público era bastante restrita. Esses pressupostos embasam esta pesquisa e visa a apresentar um breve relato sobre a relação entre a expansão da malha urbana de Presidente Prudente-SP, e a implantação de escolas de ensino fundamental I (antigo primário - escolas primárias) nessa cidade, entre os anos de 1945 e 1964. Verificou-se que a gestão pública local demonstrava alguma preocupação com questões educacionais. A metodologia teve como base levantamentos históricos e mapeamentos urbanos.

Palavras Chave: Políticas públicas de educação, Ensino fundamental, Expansão territorial urbana, República Populista, Presidente Prudente.

\section{ELEMENTARY PUBLIC SCHOOL IN PRESIDENTE PRUDENTE-SP IN THE POPULIST REPUBLIC IN BRAZIL (1945-1964)}

\begin{abstract}
In 1979, the first Brazilian legislation was passed on division of urban land, which also required areas for deployment of utility equipment. Prior to that date, there was no control and/or direction of the growth of the city. At the same time, the supply of public education was very restricted. These assumptions underlie this research that intends to present a brief report on the relationship between the growth of Presidente Prudente-SP, and the establishment of elementary schools in this city, between the years 1945 and 1964. It was found that the local public administration showed some concern with educational issues. The methodology was based on historical surveys and urban mapping.

Keywords: Public policies of education, Elemantary education, Urban land expansion, Populist Republic, Presidente Prudente
\end{abstract}




\section{INTRODUÇÃO}

Os anos de 1930 a 1945 são conhecidos como Estado Novo na política brasileira, ou Era Vargas, por meio do governo centralizador de Getúlio Vargas. A redemocratização institucional do país após o final desse governo, no plano nacional, e o final da II Grande Guerra (1945), no plano mundial, referem-se ao período marcado por processos sociais e históricos mapeados conhecidos como República Populista ou Brasil Nacional-Desenvolvimentista (CRUZ, 2013).

Assim sendo, no período entre 1945 e 1964 foi marcado por práticas democráticas no Brasil, com discussões políticas livres e desenvolvimento de movimentos populares, e também com eleições diretas para todos os cargos e níveis - de vereadores a presidente (PILETTI, 1997).

No entanto, manteve-se a centralização política junto ao governo federal, como a política educacional brasileira. Importante destacar que, o Município somente passou a integrar os entes federativos a partir da Constituição Brasileira de 1988. Ou seja, não havia definições claras sobre o desenvolvimento urbano de cunho local. Essas eram resultados de propostas e interesses federais e/ou estaduais.

Sobre as diretrizes para controle do espaço urbano, somente em 1979 foi aprovada lei federal (Lei 6.766/1979) que versa sobre o parcelamento do solo urbano e os percentuais que devem ser disponibilizados para lazer usos institucionais, entre eles as escolas públicas.

Nesse contexto, este artigo busca identificar o processo de expansão territorial urbano de Presidente Prudente no período conhecido como República Populista, entre os anos de 1945 a 1964, quando ocorreu o início do Governo Militar no Brasil. A metodologia utilizada foi baseada em levantamentos teóricos, históricos e documentais.

\section{BREVE ANÁLISE POLÍTICA EDUCACIONAL NO BRASIL NA REPÚBLICA POPULISTA}

A migração e a imigração que ocorreram, no Brasil, foram bastante importantes na formação das cidades brasileiras. E, com a Proclamação da República, muitas alterações foram desejadas, entre elas a ampliação do quadro escolar brasileiro, incluindo as mulheres na estrutura de ensino público. Pois segundo a ideia republicana brasileira do final do século XIX, a educação era fundamental, ou ordem propulsora, para o progresso; sendo a escola o local onde a educação deveria ser ministrada formalmente (SAVIANI et al, 2006).

Segundo Faria Fo. e Vidal (2000), a partir de meados da década de 1890, inicialmente no Estado de São Paulo, a proposta de grupos escolares tornou-se mais acabada, que visava à divulgar a República e seu projeto de educação. Isso resultou em edificações monumentais.

Souza (1998) afirma que os grupos escolares também tinham grande relação com os projetos políticos educativos das escolas seriadas. E Saviani et al (2006) informam que as escolas brasileiras, entre 1890 e 1930, seguiram a ideologia iluminista. Analisando a arquitetura escolar do final do século XIX, Wolff (1992) afirma que ela nasceu focando no papel de propagar a ação de governos por meio da educação.

Durante o governo de Getúlio Vargas (1930-1945), a educação e a implantação de escolas foram consideradas como questão nacional. Anteriormente a esse período, os Estados (antigas províncias) eram os responsáveis pelo ensino fundamental (escolas primárias). No entanto, com o controle centralizado da administração da educação, voltou-se à regulamentação da educação brasileira em âmbito nacional (SAVIANI et al, 2006).

No período pós II Guerra Mundial, Pasinato (2013) relata que o Brasil iniciou a República Populista, que se estendeu até o ano de 1964 com o Governo Militar, sendo que na economia, houve substituição do modelo agroexportador pelo modelo nacional desenvolvimentista. Nessa situação, o governo então passou a interferir cada vez mais na economia do país, criando classes industriais e ampliando o poder dos Estados.

Em 1946, nova Constituição Federal foi sancionada, e reintroduzia alguns princípios que haviam sido eliminados devido à Constituição de 1937, entre eles: a educação como direito de 
todos á escola primária (ensino fundamental I) obrigatória, o ensino primário gratuito a todos (PILETTI, 1997). A CF de 1946 também definiu a União com a competência para fixar as diretrizes e as bases da educação nacional, embora o art.171 informava que "[...] do ponto de vista da organização da educação escolar, mantém-se a orientação de que os Estados e o Distrito Federal organizem seus sistemas de ensino" (SAVIANI, 1987, p.31).

No ano seguinte, foi composta comissão de educadores para discutir sobre o projeto de lei de Diretrizes e Bases (LDB) da Educação Nacional, lei que regulamentaria o artigo constitucional. No entanto, apenas 15 anos depois foi aprovada a primeira LDB - Lei no. 4.024/1961.

Segundo Pasinato (2013), entre os anos de 1956 e 1961, no governo de Juscelino Kubistchek, foi implantada política diferenciada, o 'Plano de Metas', a qual empreendeu diversas realizações desenvolvimentistas.

Kubistchek, na tentativa de fazer jus às teses defendidas pelo nacionalismo, aumentou as despesas públicas com o ensino e principalmente com a superior, favorecido em relação ao primário. Após Juscelino, o populismo ocorreu por meio de Jânio Quadros (1961), que renunciou no mês de agosto do mesmo ano do início de seu mandato. De 1961 até 1964, João Goulart permaneceu como Presidente da República, conhecido politicamente como o "herdeiro político de Vargas".

Nesse mandato, foram apresentadas as "Reformas de Base" no campo agrário, bancário, administrativo e da educação; a a rede escolar foi ampliada sendo abertas unidades no campo, por meio de propostas de construção de escolas rurais simples, sem padrão definido. Também foi proposto o Plano Nacional de Alfabetização, inspirado no "método que alfabetizava em 40 horas", de Paulo Freire (PASINATO, 2013).

Pasinato (2013) informa que o sistema escolar buscava a intensificação da sua difusão, principalmente no período de inovações tecnológicas e de industrialização do país, onde se necessitava de mão de obra qualificada o suficiente para manuseio de tais tecnologias. Nesse contexto, o Estado ampliou o investimento na educação, sendo fator fundamental para a posterior busca por empregos e essencialmente para atingir metas de desenvolvimento do país.

A grande disseminação de educação ocorreu nas décadas de 1950 e 1960, tendo as escolas como poderosa fonte de integração social e desenvolvimento, unidos ao fator econômico positivado no Brasil. A ideia de que a educação aumentaria a produtividade do indivíduo foi adotada e contribuiu para seu investimento em busca pela prosperidade do desenvolvimento econômico. E, a partir dos anos 1950, a simplicidade e a economia na construção das escolas estavam cada vez mais disseminadas, alterando-se as concepções sobre os espaços escolares (FARIA Fo. e VIDAL, 2000).

Em 1961, ocorreu a sanção da Lei no. 4.024 - Lei de Diretrizes e Bases (LDB) da Educação Nacional, que se aproximava do Plano Nacional de Educação (PNE). No entanto, em 1964, foi iniciado novo processo político no país, por meio do Governo Militar. Aspectos da educação foram alterados, mantendo-se a centralização da administração educacional.

O controle do espaço urbano adquiriu novas diretrizes por meio do Serviço Federal de Arquitetura e Urbanismo - SERFAU, que instituiu metodologia e estimulou a elaboração de planos diretores locais - Plano Diretor de Desenvolvimento Integrado - PDDI (HONDA, 2011). Em 1979, por meio da Lei 6.766, a expansão territorial urbana e aprovação de novos loteamentos nas cidades brasileiras adquiriram controle.

\section{EDIFICAÇÕES ESCOLARES}

A partir de meados da década de 1890, a proposta de grupos escolares visava a divulgar a República, que resultou em edificações monumentais, construídos a partir de plantas-tipo, simétricos, em torno de um pátio central que separava meninos e meninas, podendo ser de um ou 
dois pavimentos, com grandes pés-direitos (FARIA Fo. e VIDAL, 2000; SOUZA, 1998; SAVIANI et al, 2006).

A partir da década de 1920, os projetos dos grupos escolares sofreram alterações e objetivavam a homogeneização da mensagem estética, cultural e ideológica nos edifícios escolares, propondo o estilo neocolonial como padrão. No entanto, os custos de construção dessa tipologia eram bastante altos, indo na contramão da necessidade de ampliação da rede de escolas de ensino público primário (atual fundamental I) (FARIA Fo. e VIDAL, 2000).

E, a partir dos anos 1930, no Governo de Getúlio Vargas (1930-1945), a administração escolar passou a ter um controle centralizado. A rede escolar foi ampliada sendo abertas unidades no campo, por meio de propostas de construção de escolas rurais simples, sem padrão definido a partir do final da década de 1940 (SAVIANI et al, 2006; FARIA Fo. e VIDAL, 2000).

Em 1946, nova Constituição Federal foi sancionada, "que concedeu à União a competência para fixar as 'diretrizes e bases da educação nacional'". Em 1947, foi composta comissão de educadores para discutir sobre o projeto de lei de Diretrizes e Bases (LDB) da Educação Nacional (SAVIANI, 1987). Esse projeto foi convertido em lei em dezembro de 1961, e sofreu grandes alterações em 1968 e 1971, sendo que em 1996 ela foi substituída pela atual LDB (SAVIANI et al, 2006).

E a partir dos anos 1950, novamente com Getúlio Vargas como Presidente da República (1951-1954), a simplicidade e a economia na construção das escolas estavam cada vez mais disseminadas, alterando-se as concepções sobre os espaços escolares, otimizados e com redução dos custos. Compactuava-se com o repertório formal modernista, por meio de combinações de sólidos geométricos, linhas puras, sem ornamentos, sem simetria e com utilização de protetores solares (AZEVEDO, BASTOS, BLOWER, 2007).

Já na década de 1970, verifica-se a busca por sistematização e padronização de projetos escolares. E, em 1975, devido ao aumento da demanda por vagas no Estado de São Paulo, o Governo Estadual buscou racionalizar o sistema projetivo, reduzindo os custos das obras e agilizando suas construções, que culminou na criação da Companhia de Construções Escolares do Estado de São Paulo (CONESP) (AZEVEDO, BASTOS, BLOWER, 2007).

\section{PRESIDENTE PRUDENTE-SP E A EXPANSÃO TERRITORIAL}

Presidente Prudente é cidade localizada no oeste paulista. Sua colonização foi apoiada na produção agropecuária e na implantação de estação ferroviária da Ferrovia Sorocabana, no início do século XX (inaugurada em janeiro de 1919). E sua estrutura urbana teve relação direta com a abertura de dois loteamentos: Vila Goulart e Vila Marcondes. A localização da Vila Goulart, em frente à estação ferroviária e com topografia mais suave, acabou por definir o papel central desse loteamento, que deu origem ao centro principal da cidade.

Assim, a Vila Goulart assumiu o papel de centro comercial e área residencial das famílias mais abastadas, enquanto a Vila Marcondes passou a atrair as empresas de beneficiamento agrícola ao longo da linha ferroviária e bairro residencial das classes mais baixas. Em 1921, o município de Presidente Prudente foi criado legalmente, como centro político e administrativo regional. A cidade assumiu papel de base comercial, de prestação de serviços e de beneficiamento da produção agrícola regional (HONDA, 2000).

Percebe-se maior dinamismo na expansão da malha urbana na direção sudoeste, como prolongamento da Vila Goulart. Nos vinte e cinco primeiros anos de criação de Presidente Prudente, a cidade apresentou significativa expansão territorial, mas marcada pela informalidade na organização fundiária, atingindo diretamente a produção da cidade. O período compreendido entre a segunda metade da década de 1950 e a de 1960 ficou marcado por pequeno crescimento espacial urbano, quando comparado ao verificado nos anos anteriores (HONDA, 2011). 
A partir da mudança do sistema de governo em 1964, com o Governo Militar no nível nacional, Spósito (1990) afirma que ocorreu certa moralização urbana prudentina, motivada pela possibilidade de ampliação da arrecadação municipal, pelo Poder Público, tendo provocado regularização de loteamentos, lotes e de áreas devolutas no interior do perímetro urbano. $E$, entre as décadas de 1960 e 1970, percebe-se aumento da população, ampliação do quadro industrial (com desvinculação da produção agrícola local) e desenvolvimento das atividades terciárias (HONDA, 2011).

\section{EDIFICAÇÕES ESCOLARES EM PRESIDENTE PRUDENTE-SP}

A primeira vila aberta em Presidente Prudente foi a Vila Goulart em 1917. No ano de 1920, foi iniciada a instalação de sua primeira estrutura educacional, a Escola Reunida, com quatro salas, duas para meninos e duas para meninas. Três anos depois, em 1923, segundo Abreu (1972, apud MARIANO e RIBEIRO, 2012) houve ampliação do número de crianças em idade escolar, verificando-se a necessidade de se criar mais duas salas, que ocorreu por meio da abertura de outra Escola Reunida; somando 194 crianças matriculadas (96 meninos e 98 meninas) no final de 1924.

Essa estrutura funcionou até o ano de 1925, ano que foi instalado o primeiro Grupo Escolar. Nesse período, foram instaladas outras escolas reunidas, na Vila Marcondes e na Vila Nova. Após 1930, as escolas reunidas foram transformadas em Grupo Escolar (MARIANO, 2011). No entanto, em 1938, devido a decreto governamental, os grupos escolares foram unificados ao primeiro em nova edificação. O segundo Grupo Escolar foi executado em 1945, renomeado em 1950 como 'Grupo Escolar Professor Adolpho Arruda Mello', em terreno atrás da catedral.

E, a partir do ano de 1945, algumas outas edificações escolares foram executadas na cidade de Presidente Prudente, reduzindo a carência desse serviço público no município que crescia significativamente. Destaca-se que até o ano de 1979 não havia legislação no Brasil que relacionava a abertura de novos bairros com a oferta de serviços públicos, ou seja, as implantações de unidades escolares ocorreram sem uma diretriz clara ou planejamento local.

Podem ser verificadas na figura 2 as escolas públicas de ensino fundamental I que foram implantadas no período de 1945 e 1964 em Presidente Prudente. Apesar da não existência de diretrizes legais para a implantação e/ou localização das unidades escolares, verifica-se que nessa cidade houve espraiamento desses equipamentos na malha urbana, ou seja, dez (10) novas unidades escolares foram implantadas em áreas de expansão territorial urbana, de forma a aproximá-las das áreas residenciais de forma significativamente espalhada na malha.

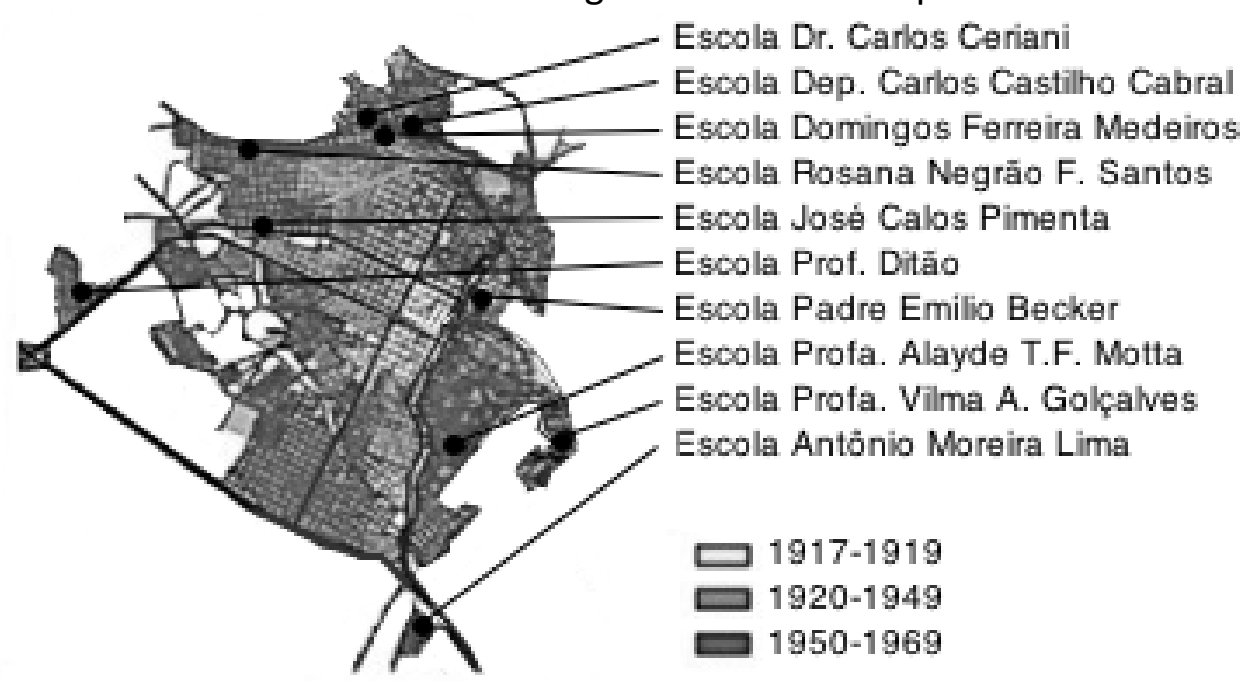

FIGURA 01. Mapeamento das edificações escolares de ensino fundamental I implantadas entre 1945 e 1964

(Fonte: Autores, 2016). 
Alguns dos loteamentos abertos além da malham urbana, receberam unidades escolares de ensino fundamental I - ensino primário - durante a ocupação por seus residentes, como pode ser observado nos bairros Jardim Monte Alto e Vila Nova Prudente, o primeiro na região oeste, além Av. Cel Goulart e o segundo além Rod. Raposo Tavares, próximo ao Distrito Industrial.

\section{CONSIDERAÇÕES FINAIS}

O período de o Governo Militar tornou-se fundamental para as mudanças urbanas apoiadas na normatização dos processos intra-urbanos. No entanto, no período anterior - 19451964 entre o final da Era Vargas e o início do Governo Militar, apesar da não relação direta entre população e unidade escolar por meio de leis e diretrizes de planejamento territorial urbano, é possível verificar que havia, em algumas cidades, a preocupação com o acesso da criança à escola.

Esse fato aconteceu na cidade de Presidente Prudente, no estado de São Paulo, podendo ser verificado o espraiamento das unidades escolares implantadas na malha urbana no referido período. Foram dez escolas executadas na cidade entre 1945 e 1964, com todas em áreas de expansão territorial urbana ocorrida após 1950.

Dessa forma, verifica-se que a gestão pública local demonstrava alguma preocupação com questões voltadas à política educacional, mesmo antes da obrigatoriedade de planos diretores municipais.

\section{REFERÊNCIAS BIBLIOGRÁFICAS}

AZEVEDO, G.A.N.; BASTOS, L.E.G.; BLOWER, H.S. O moderno já passado - o passado no moderno. Anais do III Seminário Projetar. 2007.

BRASIL. Lei 6.766. Lei sobre Parcelamento do Solo Urbano. 1979.

BRASIL. Constituição Federal Brasileira. 1988.

CRUZ, M.V. Brasil Nacional-Desenvolvimentista (1946-1964). Revista Pedagogia ao Pé da Letra. Manaus. 2013. pp.24-29.

FARIA Fo., L.M.; VIDAL, D.G. Os tempos e os espaços escolares no processo de institucionalização da escola primária no Brasil. Revista Brasileira de Educação. No. 14, pp.19-35. 2000. Disponível em: http://www.scielo.br/pdf/rbedu/n14/n14a03.pdf.

HONDA, S.C.A.L. A centralidade urbana em Presidente Prudente. Dissertação (Mestrado) Universidade Presbiteriana Mackenzie, São Paulo, 2000

HONDA, S.C.A.L. Habitação de Baixa Renda como Produto do Capital - o Programa de Arrendamento Residencial (PAR) em Presidente Prudente - SP. Tese (Doutorado) - Universidade Presbiteriana Mackenzie, São Paulo, 2011.

MARIANO, J.L.M. A implantação da escola primária graduada em Presidente Prudente-SP: as contribuições das professoras primárias (1925-1938). Dissertação (Mestrado) - Universidade Federal de São Carlos, São Carlos, 2011.

MARIANO, J.L.M.; RIBEIRO, A.I.M. De Escolas Reunidas a Grupo Escolar: os primórdios da educação em Presidente Prudente (1921-1925). Colloquium Humanarum, vol. 9, n. Especial, jul-dez, pp.777783. 2012. Disponível em: http://www.unoeste.br/site/enepe/2012/suplementos/area/Humanarum/Ci\%C3\%AAncias\%2OHu 
manas/Educa\%C3\%A7\%C3\%A3o/DE\%20ESCOLAS\%20REUNIDAS\%20A\%20GRUPO\%20ESCOLAR\%20 OS\%20\%20\%20\%20\%20\%20PRIM\%C3\%93RDIOS\%20DA\%20EDUCA\%C3\%87\%C3\%830\%20EM\%20P RESIDENTE\%2OPRUDENTE\%20\%20\%20\%20\%20\%20(1921-1925).pdf

PASINATO, D. Educação no período populista brasileiro (1945 - 1964). Semina, Passo Fundo, v. 12, n. 1. 2013. Disponível em http://www.upf.br/seer/index.php/ph/article/view/3647.

PILETTI, N. História da educação no Brasil. $7^{\text {a }}$.ed. São Paulo: Editora Ática, 1997.

SAVIANI, D. Política e Educação no Brasil: o papel do Congresso Nacional na Legislação do Ensino. Campinas: Autores Associados, 1987.

SAVIANI et al. O legado educacional do século XX no Brasil. 2a.ed. Campinas: Autores Associados, 2006.

SOUZA, R.F. Templos de civilização. São Paulo: Ed. UNESP. 1998.

SPÓSITO, E.S. Produção e apropriação da renda fundiária urbana em Presidente Prudente. Tese (Doutorado) - Universidade de São Paulo, São Paulo, 1990.

WOLFF, S. Espaço e educação. 1992. Dissertação (Mestrado) - FAU-USP, São Paulo, 1992. 